\title{
Theories $\mathrm{X}$ and $\mathrm{Y}$ in Combination for Effective Change during Economic Crisis
}

\author{
Jacques Touma \\ Lebanese American University, Byblos, Lebanon \\ Email: jacques.touma@lau.edu.lb
}

How to cite this paper: Touma, J. (2021). Theories $\mathrm{X}$ and $\mathrm{Y}$ in Combination for Effective Change during Economic Crisis. Journal of Human Resource and Sustainability Studies, 9, 20-29.

https://doi.org/10.4236/jhrss.2021.91002

Received: January 5, 2021

Accepted: February 19, 2021

Published: February 22, 2021

Copyright $\odot 2021$ by author(s) and Scientific Research Publishing Inc. This work is licensed under the Creative Commons Attribution International License (CC BY 4.0).

http://creativecommons.org/licenses/by/4.0/

(c) (i) Open Access

\begin{abstract}
It has been a fact that sustainability and employee turnover in corporations rely heavily on the different styles of management practiced at given companies nowadays. This paper addresses both theories X and Y of Mc Gregor in economic crisis, where $\mathrm{X}$ is the one that might get the poor results focusing on instrumental, physiological values comparing to theory $\mathrm{Y}$ where managers are effective leaders with better performance and terminal values promoting self-esteem and actualities. The purpose of this paper is to analyze both theories and determine the effective way to reach the ultimate results. Mc Gregor's philosophy insists on two fundamental approaches to manage people while combining additional factors other than human nature such as the human relations can play a positive role for effective change. This paper combines a realistic management style to the traditional known autocratic $(\mathrm{X})$ and democratic ( $\mathrm{Y}$ ) styles during economic crisis. Theory $\mathrm{X}$ and $\mathrm{Y}$ are two different management styles with certain philosophy interpreted by each style manager. They both look at ways and means on how to motivate employees and therefore have a feel of characters of their workers. Each theory tackles its philosophy from its end, for example, theory $\mathrm{X}$ believes pushing employees to work by having punishment and rewards can actually be a motivational factor, while theory Y promotes the self-management, self-esteem, management by objective leading to intrinsic and extrinsic rewards.
\end{abstract}

\section{Keywords}

Theory X, Autocratic, Theory Y, Democratic

\section{Theory X}

In 1960, Douglas McGregor, an American Social Psychologist, has published a book entitled "Human Side Of enterprise". This book describes the development 
of two new theories $\mathrm{X}$ and $\mathrm{Y}$. Both of them refer to a new style of management and human motivation.

Theory $\mathbf{X}$ is an autocratic management style where the manager has the centralization of power and takes decision without taking the opinion of colleagues at work. It reflects on the personality of the manager which reveals on the outside a confident image and well hands-on managed business.

McGregor believed that theory $\mathrm{X}$ stresses on the satisfaction of the lower needs where extrinsic rewards are on pay and benefits. McGregor believes that people by nature dislike and avoid work. Accordingly, they should be forced, monitored, controlled and directed either by punishment or rewards to keep them working (McGregor, 1960).

Theory $\mathrm{X}$ has a fanatical, narrow minded, poor listener, short tempered, arrogant style of management and has no interest in the human issues in general. It assumes that people by nature are not willing to do their jobs and that their assigned duties are not done because they always find ways not to finish them. They have no confidence and are not trusted by the organization. The environment is described by all means on how to deal with pessimistic and lazy people while finding ways to comprehend with the management style. As per the theory $\mathrm{X}$, a successful company has better productivity attained when the management staff forces the employees to finish their duties at work. A strict control and behavior monitoring are performed on the workers in order to avoid slacking towards the task at hand. Motivation is achieved only through punishment, threats, fear and special rewards.

A management can be "hard" or "strong" (The Human Side of Enterprise). The manager should have close supervision and direct control over the employees' behaviors. McGregor believed that when a person has shelter and food, it means that his physiological needs are satisfied which extends from birth to death (The Human Side of Enterprise). Once physiological needs are satisfied, man moves to safety where protection against danger harm, which leads to security, should be present. People do not like to be responsible; they only want security and a little ambition.

In this theory, people are only interested in both physiological and safety needs rather than higher needs. Due to the business globalization, such as standards of living, education level, political nature affected possibilities and restrictions of organizational behavior, several factors have changed career paths, job securities and job satisfactions.

During the 90 s, workers used to be afraid to lose their jobs since it was harder to find a new job than it had been twenty years ago. Several companies reduced their workforces which made employees wonder about the companies' loyalty towards them since these organizations had dropped their loyalty at first (Camp, 1994; Ciulla, 2000). It made employees accept lower salaries within stable jobs and lower risks, rather than choosing higher salaries with greater risks (Hart, 1998). This had an outcome whereby managers could not link the individual needs to the needs of the organization since the workers did not feel that the or- 
ganization is loyal towards them. Also, people were dissatisfied with their jobs. This dissatisfaction was high amongst minorities and women (Schmidt, 1999) affected by gender, permanent status, position and salary.

Theory $\mathrm{X}$ persists not due to the nature of jobs, but because different people have personalities that respond more to this theory. Management is not giving orders to employees where the needs of the organization and the needs of the employees are balanced. The strength of theory X helps managers understand the thoughts that focus on how employees relate to work (Kirton, 1976).

In Theory $\mathrm{X}$, centralization of power leads employees to dissatisfaction, as it also forces them to please the manager. The manager has no interest in the human issues, and makes people work under pressure.

The employees have no ambition and avoid responsibilities. They have no confidence and are not trustworthy. Theory $\mathrm{X}$ has a direct effect on the organization structure where salaries are paid based on the position of the employee rather than personal qualifications. The employee is always to be blamed without checking if the problem is from the system, policy or lack of training. Here the manager stresses on the punishment or reward of the employees in order to make them work.

\section{Theory Y}

As for the Theory $\mathrm{Y}$, the distribution of mental effort at work is expected rather needed. The commitment is considered one of the important behaviors related directly to the individual's achievement. The employee of this environment will be characterized by the responsibility towards the company and the tasks given that show high level of creativity to solve the problems facing the organization.

Beside employees' major role described by Theory Y, Managers' role is equally important specially that their role changed from being autocratic in Theory $\mathrm{X}$ to a more democratic leadership style. In fact, Y Managers consider people committed to work and responsible to find solutions. They are totally convinced that their employees do not only accept responsibilities, but they seek for it. These managers are more participative and interact better with all the team members therefore delegate more responsibilities. They believe in teamwork and that their employees have high degrees of imagination and creativity to identify problems and end up with the right solutions.

As for Theory $\mathrm{Y}$, the best way to manage people is to manage as little as possible (Stewart, 2010). A Y manager will help others to be successful in order to succeed. Managers should be aware that business is all about people, so if we trust people, they will trust us back and they will be more productive. In fact, most of the people nowadays are $\mathrm{Y}$ people especially when it comes to motivational tasks.

As per McGregor, people beliefs will have a direct impact on their behavior inside the work. Managers should support higher levels of mind freedom and responsibilities to improve and increase productivity. They should start to be- 
lieve and act as one of the team by adopting less autocratic type of management. All decisions should be shared and negotiated by the team in order to have the best decision. By promoting creativity and delegating more responsibilities to employees, the company effectively will achieve its goals and perform at best.

Recent studies revealed that Theory $\mathrm{Y}$ is most and better adapted for organizations that need problem solving and individual participation in decision making, so it fits more the environment where creativity, problem solving, and scientific issues exist. A good environment for theory $\mathrm{Y}$ to be implemented is in technology industries and internet companies where managers have shown high levels of flexibility and understanding allowing employees to accomplish their work from home. Moreover, employees have shown their satisfaction even if they consider that they are less paid and they do not have enough vacations (Morse and Lorsch, 1970).

Before the distribution of work, companies must decide about how to deal with the employees. Usually, this relation is defined by the related terms and conditions that should be implemented. The beliefs held by the employee towards these internal regulations are known as the psychological contract (Robinson et al., 1994). More specifically, it is what the employee expects from the organization and vice versa in terms of inputs and outcomes.

Theory Y managers have better results in leading people to grow and develop. According to McGregor "Man is a waiting animal and as soon as one his needs is satisfied, another appears in its place". By adopting the Theory Y management style, people will be more productive, responsible, motivated, and higher levels of self-esteem will be achieved. Theory Y managers give employees ways to solve and improve work. It is a democratic style of management allowing people to be part of the decisions. Therefore, managers of the Theory $\mathrm{Y}$ are liberal managers that influence people and believe in them for a better organization. Given all the characteristics above, psychological contract fulfillment is more related to Theory Y than Theory X. Thus, theory Y offers a new aspect of management that gives more attention to the human side (Bobic, 2003).

Although theory Y presents the democratic management, there are some main issues of concerns. For instance, McGregor in Theory $\mathrm{Y}$ assumes that all people are creative or at least want to be creative but the issue is that people have different personalities that respond to theory $\mathrm{X}$ more than theory $\mathrm{Y}$ in some cases.

\section{Physiological and Self-Actualization}

Records show that in the past, employees had a long path career under one or two employers. In the late nineties, workers were facing different environment since they were expected to work for six to seven employers in their careers (Hart, 1998). Employees in the majority cases were no longer loyal to one place and they believed in return that their employers have less loyalty to them (Camp, 1994; Ciulla, 2000). The reason why employees became less loyal to their companies because of job security especially after 1996 when AT \& T fired more than 
five hundred employees and other companies did the same. American workers felt the lack of job security. As a result, people started to search for jobs with higher levels of security superseding ideal jobs with terminal values and satisfaction. This brings the fact that job seekers may choose theory $\mathrm{X}$ management with better job security over $\mathrm{Y}$ especially when working environment and economic conditions are uncertain and less stable compared to 1950s and 1960s (Walesh, 1997).

This brings us to today's economic crisis where employees are struggling to find jobs to fit best their skills and knowledge. On the other hand, employers also are having difficulties in filling out positions. Before the 2019 crisis, technology and innovation were the agents of change and improvement with a lot of opportunities in the labor market. Millions of employees' today are faced with lay-offs and unknown destiny when it comes to keeping their jobs or employment seeking (Orrell et al., 2020).

Decision-makers and officials need to have the flexibility to help job seekers during economic crisis with financial resources to meet their needs and perform their potential jobs by acquiring training that fits their needs, with additional resources on services such as internet, transportation, childcare that basically ease the process of going to work and be ready for the new employment (Orrell et al., 2020).

In addition to job security that assures an income through a job, the United Nations identified other human securities that can be possibly linked to job security such as food security which is on one end the access to food, economically speaking which can be vital to the wellbeing of employees that affects tremendously their performance. Health security is another human security concern mentioned as well, by having a job security, the employee would have access to health care and many other benefits. Human security has to be provided to people and employees not only to secure the basic needs of Maslow's hierarchy model but also to add to that political stability, environmental security and also community security, a sense of belonging to share common interest and behaviors (Hamourtziadou, 2019).

Although Mc Gregor fundamentally altered the course of management theory years ago, three core elements of his theory have undergone significant erosion (Bobic, 2003).

Firstly, many employees today find themselves in a situation that inspires neither satisfaction nor job fidelity. Secondly, Maslow's hierarchy of needs theory has some critics. Lastly, studies on human motivation no longer define "creativity" plainly as "innovation".

Employees, in the past, expected long careers subsequent to a given career path under one or two employers. However, before the economic crisis employees faced essentially different environment. In a Shell Corporation survey, more than 52 percent of the 1100 surveyed workers expected to hold five or more jobs in their careers. Moreover, workers engage in a "constant" search for new employments, regardless if they are satisfied in their current jobs. This undoubtedly contrasts with Mc Gregor hypothesis that career would exist largely 
within the same organization. Sixty-five percent of the Shell corporation surveyed workers were "only slightly" loyal or "not too loyal" to their employers. Moreover, 75 percent of the respondents claimed that companies were either "somewhat loyal" or "not loyal at all" to them (Hart, 1998).

Maslow's hierarchy has been subject of debate with plentiful critics challenging its theoretical and empirical foundations (Heylighen, 1992, Rowan, 1998).

Researchers have pointed out that Maslow did not succeed in considering key essentials of human motivation (Bobic, 2003). Moreover, Rowan (1998) feared that the hierarchy's unprincipled structure would lead to ignore ethical and political considerations other than the self. Most critics also point to the fundamentally western and specifically American bias originated in Maslow's perception of self-actualization (Bobic, 2003).

Most of the common criticisms of Maslow's hierarchy are that the model has never been validated empirically (Bobic, 2003). Heylighen (1992) disputed that Maslow's concept of self-actualization was confusing and that a theory based on the satisfaction of needs was not enough to explicate human behavior.

\section{Findings and Analysis}

Workers' career paths, workers' job security, workers' job satisfaction, and the degree to which worker's prefer security over creativity are four aspects of work environment that have been dramatically distorted during the latest economic crisis. A survey was conducted in Lebanon in the last quarter of 2020 showed that employees are no longer looking to switch jobs because of the external factor. Almost 42 percent were satisfied in their jobs knowing that they were getting a pay cut or delayed partial payments due to the current crisis.

The study also showed that employees are putting more efforts to sustain the business, and this fact created a bond that was not there prior to the economic crisis. Employees revealed far less security in their prediction for sustained employment at any given organization than they did in the past. In this study, employees are more afraid of job loss and are less confident about the likelihood of finding new employment than they had been prior to the economic crisis. Employees preferred job security to "finding the ideal job" by a margin of three to one. In the same context, 56 percent of the surveyed employees chose the stable job with fewer monetary rewards and few risks over a job with greater financial success but with greater risk.

This study also demonstrates that when there is an external factor such as economic crisis, the human expectation in terms of satisfaction and expectation changes drastically. Employees satisfaction even on the psychological needs becomes less significant although once basic needs are met, it is of human nature to aim for esteem needs and self-actualization.

\subsection{Effective Change}

Things have changed and most managers today are well exposed to all sorts of training, education of how different style of management can affect the corpo- 
rate performance of their firm yet the presence of both micro and macro managers exist and this is part of the human nature. The other part is the human relations which usually plays an important role in the advancement of the organizations. The combination of both human nature, human relations and how well controllable they can be are the key constitutional of whether an effective positive change in companies is obtainable.

For instance, if conflicts among people exist due to misunderstanding based on some false assumptions, the eliminations of such assumptions will develop the state of peace therefore a positive change happens. In case the assumptions are true thus there is that case real variation of interest therefore the solution depends on the system of their relations at first followed by their attitudes towards each other (Stewart, 2010).

Most people are averse to change because they feel they need to do more work that they were not supposed to do. For an effective change, employees must recognized what is it for them, for their benefit to change and how this will affect their sustainability as an organization in the future. Answers to questions like what does the organization do best in the eyes of customers; what are the external factors that threaten the way the organization conducts business; what are the elements needed to have the organizations get back to its core valued products and services? Once employees share their ideas and ideas become coherent than an effective change could happen (O'Neil, 2018).

An effective change can be implemented in both theories X and Y. The effective change is to get things done the fastest possible way without wasting any non-value added time yet perform the quality and requirement needed for the job from the resources including human available to the manager. For instance, in case where employees like to be directed (X type) then the manager should push to keep them motivated and make appropriate decisions since the authority is assumed unquestionable.

On the other end if the employees are self-motivated and self-challenged ( $\mathrm{Y}$ type) therefore the manager should delegate more responsibilities, give more challenging assignments, let the employees seek, plan, organize their own tasks to accomplish the assignments given with minimal yet accurate supervision (Geber, 1987).

An effective modern tool which has been evolving is the use of the Enterprise Resource Planning (ERP) in most companies today by both style managers. Regardless of whether there is an X type or a Y type manager the use of ERP can advance and have an effective change. For instance, in a $\mathrm{Y}$ environment type, employees may have access different screens relating to their job and can place orders based on the analysis of inputs and things would flow smoothly. The case where employees are trusted fully to perform their jobs and select the best options for the company.

On the other end (X type), employees through the use of ERP have limited screens access and must go back to their supervisors for confirmation prior to placing an order, an additional built-in and customized screen allowing the 
manager to check the order prior to placing it on the system. The case where the employees are less trusted and performing certain tasks might require additional time from the micro manager.

Even small companies today can afford the implementation of Postmodern ERP which is a solution on clouds, very affordable, proportional to the amount of users that actually use the system. Postmodern ERP can add modules and automates businesses and operational capabilities with customized screens and approval based on the management requirement within any given company.

Adding to above, the implementation of Enterprise Risk Management (ERM) which is a tool to manage risks of a firm in a holistic way especially if there have been some negative decisions implementing change in the organization. Top managers with good reputation that delivers poor performance in the beginning must incorporate this tool that can tackle as well top management retention in an organization, part of managing effective change (Altuntas et al., 2020).

In addition to technology, culture and personality of employees, an important measure that plays a role in what sort of style is more applicable and can score greater effectiveness is the situation. For instance, if working on a particular project, a new concept, an employee might prefer a close supervision to align the needs and the details required for such execution. On the other end, that same employee during the working career might prefer less supervision and more dependency on his work leading to acknowledged performances (Caruth \& Handlogten, 1998).

Another factor is exposure, managers have to be exposed to different cultures to absorb the employees' differences thus its essential for managers to have international exposure and integrate with different cultures, for instance study shows that when managers are exposed internationally, they tend to have a positive effect on the organization. International experience has a great impact on strategic change and firm performance (Le \& Kroll, 2017).

\subsection{Proposed Model}

Based on the results of this study, the following model (Figure 1 below) is proposed to be implemented in any given company during economic crisis and would potentially work certainly for companies that have similar situation when it comes to using the mixed approach of theory $\mathrm{X}$ and $\mathrm{Y}$, the right combination of both.

The model addresses the fact in case of economic crisis with challenging demands when it comes to employment and retaining the right employees, the following steps are proposed:

Step 1: Consider the mixed approach of both theories $\mathrm{X}$ and $\mathrm{Y}$ to reach smooth and efficient operations.

Step 2: Integrate systems such as ERP or Postmodern ERP with the option of screen approval customization to minimize non-value added tasks and use resources more adequately. 


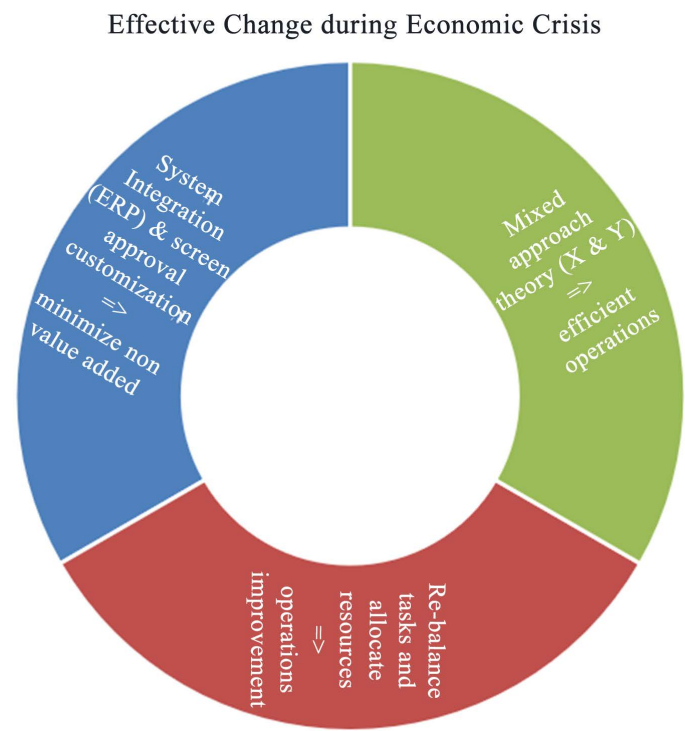

Figure 1. Proposed model for effective change.

Step 3: Re-balance work tasks and allocate resources to maximize operations performance at the same time empower supervisors to apply the new practices during economic crisis.

\section{Conclusion}

The existence of $\mathrm{X}$ and $\mathrm{Y}$ theories throughout all organizations has been revolving to the degree that the choice of management style should reflect on the different assignments which require a mixed style approach in several cases depending on the situation, flexibility with employees being managed in economic crisis, personalities of workers, previous styles exposed and accustomed to, employer's inclination toward a certain style where adaptation can happen ultimately and in progression. Determining the most effective method for reaching the organizational goals and objectives is the key element for effective positive change which should be blended to employees' satisfaction and motivation in order to sustain efficient yet effective and rewarding business through the use of system integration in such economic crisis.

\section{Limitation}

This paper addressed the human resource and its effective change when it comes to economic crisis. A limiting factor of approaching employees during crisis had a common excuse that they were overwhelmed with a lot to do in terms of sourcing materials, preparation and customer support because of the economic crisis.

\section{Conflicts of Interest}

The author declares no conflicts of interest regarding the publication of this paper. 


\section{References}

Altuntas, M., Berry-Stölzle, T., \& Hoyt, R. (2020). Enterprise Risk Management Adoption and Managerial Incentives. Journal of Insurance Issues, 43, 1-42.

Bobic, M. P. (2003). A Kind Word for Theory X: Or Why So Many Newfangled Management Techniques Quickly Fail. Journal of Public Administration Research and Theory, 13, 239-264. https://doi.org/10.1093/jopart/mug022

Camp, S. D. (1994). Assessing the Effects of Organizational Commitment and Job Satisfaction on Turnover: An Event History Approach. The Prison Journal, 74, 279-305. https://doi.org/10.1177/0032855594074003002

Caruth, D., \& Handlogten, G. (1998). The Good the Bad and the Ugly: Contrasting Management Styles. ProQuest Research Library, 50, 1.

Ciulla, J. B. (2000). The Working Life: The Promise and Betrayal of Modern Work. New York: Three Rivers Press.

Geber, B. (1987). I'm OK You're Theory X. ProQuest Research Library, 24, 1.

Hamourtziadou, L. (2019). Security Challenges of the 21st Century: New Challenges and Perspectives. Journal of Global Faultlines, 6, 121-123. https://doi.org/10.13169/jglobfaul.6.2.0121

Hart, P. D. (1998). Study \#5184. Survey Conducted for Shell Cooperation, 17-20 July.

Heylighen, F. (1992). A Cognitive-Systematic Reconstruction of Maslow's Theory of Self-Actualization. Behavior Science, 37, 39-58. https://doi.org/10.1002/bs.3830370105

Kirton, M. (1976). Adaptors and Innovators: A Description and Measure. Journal of Applied Psychology, 61, 622-629. https://doi.org/10.1037/0021-9010.61.5.622

Le, S., \& Kroll, M. (2017). CEO International Experience: Effects on Strategic Change and Firm Performance. Journal of International Business Studies, 48, 573-595. https://doi.org/10.1057/s41267-017-0080-1

McGregor, D. (1960). The Human Side of Enterprise. New York: McGraw-Hill.

Morse, J. J., \& Lorsch, J. W. (1970). Beyond Theory Y. Harvard Business Review, 48, 61-66.

O'Neil, E. (2018). Leading-Not Managing—Through a New World Order. Generations: Journal of the American Society on Aging, 42, 41-44.

Orrell, B., Bishop, M., \& Hawkins, J. (2020). A Road Map to Reemployment in the COVID-19 Economy: Empowering Workers, Employers, and States. Washington DC: American Enterprise Institute.

Robinson, S. L., Kraatz, M. S., \& Rousseau, D. M. (1994). Changing Obligations and the Psychological Contract: A Longitudinal Study. Academy of Management Journal, 37, 137-152. https://doi.org/10.2307/256773

Rowan, J. (1998). Maslow Amended. Journal of Humanistic Psychology, 38, 81-92. https://doi.org/10.1177/00221678980381008

Schmidt, S. R. (1999). Long-Run Trends in Workers' Beliefs about Their Own Job Security: Evidence from the General Social Survey. Journal of Labor Economics, 17, S127-S141. https://doi.org/10.1086/209945

Stewart, M. (2010). Theories X and Y, Revisited: Shifting the Trajectory of Civilization. Oxford Leadership Journal, 1, 1-5.

Walesh, S. G. (1997). Job Security in an Oxymoron. Civil Engineering ASCE, 67, 62-63. 